primary iron storage disease studied here this patient did demonstrate a very slow-moving iron-binding compound on polyacrylamide gels after incubation with ${ }^{59} \mathrm{Fe}$.

(3) Our choice of the word "abnormal" was unwise as we meant to indicate that the tumour ferritin was different from hepatic ferritin rather than implying a demonstrated functional abnormality. Unfortunately, further studies could not be carried out on this patient but the presence of the tumour ferritin and secondary siderosis (histologically) seemed to warrant the speculation.

ROBERT BATEY

Medical Unit,

Royal Free Hospital,

London NW3

\section{Hepatitis B and endoscopy}

SIR,-We were interested to read the recent paper by Dr D B L McClelland and others reporting the absence of transmission of hepatitis $\mathrm{B}$ by gastrointestinal endoscopy (7 January, p 23). We would like to report a similar episode which occurred in our unit in November 1974.

A 51-year-old man was admitted as an emergency with melaena. There was no preceding history of jaundice and on examination no stigmata of chronic liver disease were found. Endoscopy showed large oesophageal varices and these were identified as the source of the bleeding. A hepatitis B antigen (HBAg) assay was therefore performed and found to be positive, but owing to failure of communication this did not become known to the endoscopy team until February 1975. As at that time the endoscope was cleaned with Savlon only it was decided to screen all patients endoscoped within three weeks of the incident. These 28 patients were seen between the 81 st and 97th day after their endoscopy. Clinical examination revealed no evidence of either acute or chronic liver disease and liver function tests were normal. Immunoelectrophoresis and turkey erythrocyte haemagglutination tests for HBAg and immunoclectro-osmophoresis tests for antibody to $\mathrm{HBAg}$ (anti-HB) were negative in all patients, who were then followed up for the full incubation period of 160 days, no case of jaundice occurring.

We therefore concluded that the risk of transmitting HBAg via a contaminated endoscope must be small. To minimise this the endoscope is now soaked in glutaraldehyde for $20 \mathrm{~min}$ at the end of each endoscopy list.

A G Morgan

W A F MCADAM

Endoscopy Unit

Airedale General Hospital,

Keighley, W Yorks

B E WALKER

Chapel Allerton Hospital,

Chapel Allerton
Leeds, W Yorks

\section{Autoclavable Forrester laryngeal spray}

SIR,-I am grateful to Drs $M$ W Casewell and M T Dalton (10 September, $p$ 680) for drawing attention to the possibility of cross-infection when using the Forrester laryngeal spray. I have been in touch with Penlon Ltd, the makers of the redesigned spray, and they have reassured me that this spray is fully autoclavable. An extract from their letter reads as follows:

"The current version of the Forrester spray which has been produced for the past five years is entirely autoclavable, provided the bulb is removed. The metal components are all stainless steel, the now very limited lengths of flexible tubing have been autoclavable silicone since the production commenced, and the bottle and lid are made of TPX, which is a fully autoclavable plastic. TPX does tend to lose transparency with repeated autoclaving because of water absorption, but it is not distorted at the normal 136 autoclaving temperature.

"It is of course absolutely essential to ensure that the spray is clean before autoclaving in order to prevent blockage of the fine internal passages. These can be cleaned by filling the spray bottle with water, preferably warm, and operating the spray until the bottle is empty."

I feel, therefore, that the improvements suggested by Drs Casewell and Dalton have been adequately catered for for some considerable time, and I hope that this assurance should allay any disquiet resulting from their communication.

Alex C Forrester

Glasgow

\section{Silk sutures in the common bile duct}

SIR,-The report by Mr B I Rees and Mr G Jacob (12 November, p 1265) made the very important point that silk should not be used to ligate the cystic duct because such ligatures may find their way into the main ductal system to become the nuclei of stones or to be associated with other problems. We have recently seen a patient with both a silk ligature in the lower reaches of the common bile duct and a difficult stricture of the upper common hepatic duct and the confluence.

Cholecystectomy for stones within the gall bladder was performed in February 1976 (JMA). There had been no jaundice and there was no evidence of ductal stone or inflammation at operation. Operative cholangiography through the cystic duct was performed without difficulty; no stones or other abnormalities were seen. Since there were no operative difficulties and there was no obvious contamination of the operative site with bile, antibiotic was not given. The bile was not cultured. In the postoperative phase there was more upper abdominal discomfort than expected and some pyrexia. This settled and the patient was discharged after two weeks. There was no wound infection. Subsequently the patient had occasional episodes of upper abdominal discomfort and in September 1977 he developed jaundice. A percutaneous transhepatic cholangiogram showed a stricture at the uppermost part of the common bile duct. At operation (LHB) on 20 December 1977 induration and old granulation tissue was found around the upper part of the common bile duct at the site of the stricture. The filling defects in the lower part of the common bile duct consisted of some debris and a portion of knotted black silk, clearly the ligature previously used to occlude the cystic duct. Repair of the stricture was technically difficult as a result of biliary cirrhosis, small intrahepatic ducts, and an abnormal anatomical relationship between the portal vein and the hepatic ducts. Right hepatic lobectomy with anastomosis of the left hepatic duct to a Roux loop was performed.

It seems that a postoperative abscess might have formed alongside the common hepatic duct associated with stricture formation and the passage of the silk ligature into the ductal system. This experience confirms the view that problems can arise from the use of nonabsorbent materials around the biliary ductal system and that silk ligatures may pass into the bile ducts postoperatively.

John Maxwell ANDERSon L H BLUMGART

University Department of Surgery,

Royal Infirmary, Glasgow
Lung cancer risk in pipe and cigar smokers

SIR, - I was pleased to see the recent article by Dr J A McM Turner and others (26 November, p 1387) about cigar and pipe smokers inhaling and cancer risks. There have been many articles implying that all pipe and cigar smokers are relatively free of the high cancer risk which cigarette smokers have. The article by Dr Turner and his colleagues supports earlier work indicating that many pipe/cigar smokers do inhale, ${ }^{1-3}$ but it still does not confirm that pipe/cigar smokers who inhale actually have an increased risk of developing lung cancer similar to cigarette smokers. There has been some suggestion in the literature that the relative safety of pipe/cigar smoking may be related to different methods of curing the tobacco or different leaves used rather than inhaling. ${ }^{4}$ On the other hand there has been comment that pipe or cigar smokers who inhale may actually have a risk of developing cancer greater than cigarette smokers. ${ }^{5}$.

What is needed to answer this question is a good (ideally prospective) study of the cancer risks in pipe/cigar smokers who do and who do not inhale. This would be an extremely important and timely research, as many of the people who have given up smoking cigarettes in the past few years have taken up smoking cigars and pipes because of the alleged reduced risks of lung cancer and other diseases and it is this very group who are most likely to inhale.

STANLEY P BOHRER

University of Rochester

Medical Center,
Rochester, New York

Castleden, C M, and Cole, P V, Lancet, 1973, 2, 21 Cowie, J, Sillett, R W, and Ball, K P, Lancet, 1973 , 1,1033 Goodman, A L, Chest, 1977, 72, 33.
Passey, R D, et al, British Medical fournal, 1971, 4,
198.

British Medical fournal, 1973, 2, 172.

Goodman, A L, American Revien of Respiratory Diseases, 1976, 113, 87

rmitage, A K, et al, British fournal of Pharmacology,

\section{Smoking behaviour in medical students}

SIR,-I would like to add something to the letter from Dr I C McManus and his colleagues (21 January, p 175). It is not only the medical students at Cambridge who smoke less than expected: the habit is generally regarded by the student community as unacceptable. I would suggest that social reasons are responsible: if five people smoke simultaneously in the typical small college room inhabited by most Cambridge students the atmosphere rapidly becomes intolerable.

The fact that the medical freshmen reported in the McManus study smoke less than their non-medical peers may be that they are trying to conform to the idealised stereotype of the clean-living medical student. The example of the medical teaching staff soon shatters this illusion.

Another factor driving students to cigarette smoking is the work load. All medical courses are understandably hard work. However, it would appear that Cambridge is beginning to place demands on its medical students which they cannot meet. This has led to something of the order of $30 \%$ of second-year preclinical students failing to gain exemption for qualifying examinations in some subjects. At present we are not only producing another generation of 